\title{
Dorsomedial Prefrontal Cortex Contribution to Behavioral and Nucleus Accumbens Neuronal Responses to Incentive Cues
}

\author{
Akinori Ishikawa, ${ }^{1}$ Frederic Ambroggi, ${ }^{1}$ Saleem M. Nicola, ${ }^{1,2}$ and Howard L. Fields ${ }^{1}$ \\ ${ }^{1}$ Ernest Gallo Clinic and Research Center and Department of Neurology, University of California, San Francisco, Emeryville, California 94608 , and \\ ${ }^{2}$ Departments of Psychiatry and Neuroscience, Albert Einstein College of Medicine, Bronx, New York 10461
}

\begin{abstract}
Cue-elicited phasic changes in firing of nucleus accumbens (NAc) neurons can facilitate reward-seeking behavior. Here, we test the hypothesis that the medial prefrontal cortex (mPFC), which sends a dense glutamatergic projection to the NAc core, contributes to NAc neuronal firing responses to reward-predictive cues. Rats trained to perform an operant response to a cue for sucrose were implanted with recording electrodes in the core of the NAc and microinjection cannulas in the dorsal mPFC (dmPFC). The cue-evoked firing of NAc neurons was reduced by bilateral injection of $\mathrm{GABA}_{\mathrm{A}}$ and $\mathrm{GABA}_{\mathrm{B}}$ agonists into the $\mathrm{dmPFC}$ concomitant with loss of behavioral responding to the cue. In addition, unilateral dmPFC inactivation reduced ipsilateral cue excitations and contralateral cue inhibitions. These findings indicate that cue-evoked excitations and inhibitions of NAc core neurons depend on dmPFC projections to the NAc and that these phasic changes contribute to the behavioral response to reward-predictive cues.
\end{abstract}

Key words: anterior cingulate cortex; discriminative stimulus; nucleus accumbens core; prelimbic cortex; reward-seeking behavior; ventral striatum

\section{Introduction}

The nucleus accumbens (NAc) has long been considered a "limbic-motor interface" that facilitates appropriate responding to reward-predictive stimuli (Mogenson et al., 1980). Different subpopulations of NAc neurons are excited and inhibited by discriminative stimuli (DSs) and other cues that predict reward availability (Ghitza et al., 2003; Nicola et al., 2004b; Day et al., 2006; Wan and Peoples, 2006). Cue-evoked firing in the NAc could arise from glutamatergic projections from the medial prefrontal cortex (mPFC) and basolateral amygdala (BLA) to the NAc core (McGeorge and Faull, 1989; Sesack et al., 1989; Brog et al., 1993; Pennartz et al., 1994; O’Donnell and Grace, 1995; Zahm, 2000), as well as the dopaminergic projection from the ventral tegmental area (VTA) (Swanson, 1982). NAc cue-evoked firing is abolished by VTA inactivation (Yun et al., 2004b); furthermore, dopamine antagonists injected into the NAc reduce responding to the cue (Yun et al., 2004a,b), and manipulations that increase NAc dopamine levels increase cue responding (Nicola et al., 2005). VTA, mPFC, and BLA neurons respond to reward-predictive cues during many reward-seeking behaviors (Ljungberg et al., 1992; Muramoto et al., 1993; Schultz et al.,

Received Jan. 18, 2008; revised March 11, 2008; accepted March 19, 2008

This work was supported by funds provided by the State of California for medical research on alcohol and substance abuse through the University of California, San Francisco, by the Wheeler Center for the Neurobiology of Addiction, and by National Institutes of Health Grant DA019473 (S.M.N.). We are grateful to Dr. V. Kharazia for histology work.

Correspondence should be addressed to Akinori Ishikawa at his present address: 1-1-1 Minamikogushi, Ube, Yamaguchi 755-8505, Japan. E-mail: akinori@yamaguchi-u.ac.jp.

DOI:10.1523/JNEUROSCI.0253-08.2008

Copyright $\odot 2008$ Society for Neuroscience $\quad$ 0270-6474/08/285088-11\$15.00/0
1993; Schoenbaum et al., 1998, 1999; Takenouchi et al., 1999; Jodo et al., 2000), and dopamine is thought to enhance the glutamate-induced excitation of NAc neurons (Kiyatkin and Rebec, 1996; Nicola et al., 2000, 2004a; Horvitz, 2002; Hjelmstad, 2004). In this study, we sought to test explicitly the hypothesis that the inputs to the NAc contributing to cue-evoked excitations of NAc neurons include glutamatergic inputs from the mPFC.

Recently (Ishikawa et al., 2007), we showed that both the $\mathrm{mPFC}$ and BLA are involved in cue responding in a DS task similar to the one we had used earlier to explore the role of dopamine in cue-evoked reward-seeking behaviors and NAc neuronal firing (Nicola et al., 2004b,c; Yun et al., 2004a,b). Similar to the antagonism of dopamine receptors in the NAc, inactivation of the BLA and the dorsal mPFC (dmPFC) (including the cingulate and dorsal prelimbic cortex) impaired behavioral responding to reward-predictive cues (Ishikawa et al., 2007). Furthermore, BLA inactivation reduced incentive cue-elicited firing of NAc neurons, suggesting that BLA neurons are a critical source of excitatory input to NAc neurons that facilitate behavioral responding to incentive cues (Ambroggi et al., 2007). Here, we focus on the contribution of the dmPFC to NAc neuronal firing during the same DS task. We show that, similar to the effects of BLA and VTA inactivation, inactivation of the dmPFC profoundly reduces the firing rate of NAc neurons in response to reward-predictive cues.

\section{Materials and Methods}

Subjects. Nine male Long-Evans rats ( $\sim 350$ g on arrival) were individually housed in a colony room maintained on a $12 \mathrm{~h}$ light/dark cycle. All experiments occurred during the dark portion of the cycle. After receipt, 
rats were allowed at least 1 week of ad libitum food and water, followed by 1 week of restricted food and water before training. Animals were fed $13 \mathrm{~g}$ of BioServ (Frenchtown, NJ) formula F-173 pellets ( $1 \mathrm{~g}$ each) and $30 \mathrm{ml}$ of water per day for the duration of the experiments. Animals were weighed daily, and those showing weight loss $>10 \%$ of free-feeding weight were given additional food until their weight stabilized. All procedures were approved by the Ernest Gallo Clinic and Research Center Institutional Animal Care and Use Committee and were in accordance with National Institutes of Health guidelines.

Apparatus. Experimental sessions were conducted in an operant chamber (40.6 cm long, $40.6 \mathrm{~cm}$ wide) enclosed within a sound- and light-insulated box (MED Associates, St. Albans, VT). Two retractable response levers were situated on one wall of the operant chamber, with a reward receptacle between them. The reward receptacle contained a small well into which a liquid $10 \%$ sucrose reward was delivered using a syringe pump. Two orange houselights were on throughout experiments, and white noise $(65 \mathrm{~dB})$ was presented at all times. An additional speaker was used to present two auditory stimuli $(85 \mathrm{~dB})$. One was an intermittent $6 \mathrm{kHz}$ tone that was on for $40 \mathrm{~ms}$ and off for $50 \mathrm{~ms}$ ( $90 \mathrm{~ms}$ cycle period), and the other was a siren in which the frequency was ramped from 4 to $8 \mathrm{kHz}$ and back with a $400 \mathrm{~ms}$ cycle period.

DS task. Two auditory stimuli were presented as tone cues: a DS, which predicted reward delivery after a correct lever press during DS presentation, and a nonrewarded stimulus (NS), during which lever pressing did not trigger reward delivery. For four animals, the DS was the intermittent tone and the NS was the siren; the opposite relation held for the remaining five animals. The left lever was designated the active lever for four animals, and the right lever was designated active for the remaining five animals. Responses on the inactive lever had no programmed consequence at any time. A response on the active lever during DS presentation always terminated the DS and resulted in delivery of $50 \mu$ l of $10 \%$ sucrose into the reward receptacle. Responses during the NS and when no cues were presented had no programmed consequence. The DS was on for up to $10 \mathrm{~s}$, and the NS was on for $10 \mathrm{~s}$. Cues were presented on a variable interval schedule with an average interval of $30 \mathrm{~s}$; the DS or NS was randomly presented at the end of each interval.

Training procedures. Animals progressed through several stages of training before undergoing surgical implantation of cannulas into the $\mathrm{dmPFC}$ and recording electrodes into the NAc. In stage 1 of DS task training, food-restricted animals were introduced to the chamber. Entry into the reward receptacle or pressing either of the two levers triggered delivery of $50 \mu \mathrm{l}$ of a $10 \%$ sucrose solution. A $10 \mathrm{~s}$ timeout was imposed after reward delivery, during which reward could not be earned. After animals learned to obtain all 100 available rewards in $<1 \mathrm{~h}$, they were advanced to stage 2 . This stage consisted of a two-lever fixed ratio (FR) 1 task in which a response on either lever triggered reward delivery followed by a $3 \mathrm{~s}$ timeout. Animals remained at this stage until they learned to obtain 100 rewards in $<1 \mathrm{~h}$. In stage 3 , animals were advanced to a one-lever FR task in which pressing the active lever during cue presentation triggered reward delivery followed initially by a $10 \mathrm{~s} \mathrm{timeout.} \mathrm{The} \mathrm{cue}$ was presented at the end of the timeout and remained on until an active lever press. The timeout was increased to $20 \mathrm{~s}$ and then $30 \mathrm{~s}$ when animals obtained $>100$ rewards during the session. Lever pressing in the absence of the cue was not rewarded. Animals were advanced to stage 4 (the final DS task) when their latency to press the lever was $<15$ s after cue presentation. Animals were trained on the DS task until the NS response probability averaged $\sim 20 \%$, and the DS response probability averaged $>90 \%$. When animals met these criteria, surgery for cannula and recording electrode implantation was performed.

Surgery. Animals were anesthetized with isoflurane (0.5-2.0\%) and placed in a stereotaxic apparatus. Bilateral 27 gauge stainless steel guide cannulas (Plastic One, Roanoke, VA) were implanted posteriorly at an angle of $16^{\circ}$ from a point $4 \mathrm{~mm}$ anterior to bregma and $0.75 \mathrm{~mm}$ lateral to the midline, such that the 30 gauge injector cannulas would extend $1 \mathrm{~mm}$ below the end of the guides and reach the dmPFC. Target coordinates of the injectors relative to bregma and the top of the skull were as follows: (in $\mathrm{mm}$ ) anteroposterior (AP), +3.2 ; mediolateral (ML), \pm 0.75 , dorsoventral (DV), -3.0 (Paxinos and Watson, 1998). Recording electrode arrays (NB Labs, Denison, TX) consisted of two parallel rows of four stainless steel electrodes (eight electrodes total per array; electrode diameter, $50 \mu \mathrm{m}$ ) and were $\sim 0.7 \mathrm{~mm}$ long and $0.3 \mathrm{~mm}$ wide. They were implanted bilaterally, with the long dimension in the sagittal plane, in the core of the NAc (AP, +0.7-2.0; ML, $\pm 1.2-2.5$; DV, -6.5 to $7.5 \mathrm{~mm}$ ). Electrode arrays in seven animals were fixed in place with dental acrylic at these coordinates. In an additional two animals, movable electrode arrays were implanted bilaterally such that the tips of the electrodes were positioned at $6.0 \mathrm{~mm}$ below the skull, and the microdrive hub was cemented to the skull with dental acrylic. A silver wire implanted on the posterior cortical surface was used as a ground electrode, and a miniature connector wired to the electrodes was exposed at the top of the implant. Animals were allowed to recover from surgery for 1 week before commencement of experiments.

Electrophysiology and microinjections. Animals were retrained for at least $7 \mathrm{~d}$ on the DS task with recording cables connected. Electrophysiological recording was conducted as described previously (Nicola et al., $2004 \mathrm{~b}$ ). The recording apparatus consisted of a head stage, cable, commutator to allow the animal free movement within the chamber, and Plexon (Dallas, TX) spike-sorting hardware and software; units were isolated as described previously. All waveforms that exceeded an amplitude threshold (typically $50-75 \mu \mathrm{V}$ ) were saved to disk for later analysis. After a 60 min baseline recording session, during which animals were allowed to perform the DS task, they were removed from the behavior/ recording chamber and injected with $0.5 \mu \mathrm{l}$ of saline or a mixed solution $(\mathrm{M} / \mathrm{B})$ containing 25 or $50 \mathrm{ng}$ each of muscimol ( $\mathrm{GABA}_{\mathrm{A}}$ agonist) and baclofen $\left(\mathrm{GABA}_{\mathrm{B}}\right.$ agonist $)$ into the dmPFC. Injections were made over 2 min, with $1 \mathrm{~min}$ pre- and post-injection wait periods. All nine rats received bilateral injection of all drugs, whereas unilateral injections of saline or 25 or $50 \mathrm{ng} \mathrm{M} / \mathrm{B}$ were given to eight, nine, and six rats, respectively. In four rats, unilateral injection was performed after bilateral injection of all doses of $\mathrm{M} / \mathrm{B}$ and saline, and, in two rats, unilateral injections were performed first. The remaining three rats received each unilateral or bilateral injection in random order. In all cases, the order of drug doses was randomly chosen for each animal. After the injection, the animals were immediately reconnected to the recording apparatus and placed in the chamber for the postinjection session $(2 \mathrm{~h})$. For animals implanted with movable arrays, the electrodes were advanced at least 150 $\mu \mathrm{m}$ to search for neurons, until the neurons showed high enough signalto-noise ratios (typically $150-200 \mu \mathrm{V}$ peak-to-peak for the signal vs 25-50 $\mu \mathrm{V}$ for the noise) to isolate the waveforms.

Data analysis. In the DS task, several behavioral measures were examined: the DS and NS response ratios (proportion of these cues during which the animal made a response on the active lever), the DS response latency, and the rate of uncued responding on the active levers (the rate of responding in the absence of DS and NS). For unilateral injections, there was no difference in each behavioral measure between left and right injections, and so the averaged value of the injection of each side was used for comparisons of behavioral data. The effects of bilateral injections were analyzed using one-way repeated-measures ANOVA, followed by Fisher's PLSD post hoc test, whereas the effects of unilateral injections were compared by one-way ANOVA, followed by Fisher's PLSD post hoc test.

Spikes on each wire were resorted to eliminate noise and to capture waveforms not previously assigned to the appropriate template. When spike resorting was complete, autocorrelograms were constructed for each unit to confirm that they had well defined refractory periods (at least $2 \mathrm{~ms}$ ). Units without well defined refractory periods were either rejected or resorted. Each unit was assigned, based on its firing pattern, to at least one of the subsets of neurons exhibiting the response types described in Table 1. Incentive cue-, operant-, and receptacle exit-related responses of each unit were assessed using $0.1 \mathrm{~s}$ bin-width perievent time histograms (PETHs) time locked to each event, whereas $0.5 \mathrm{~s}$ bin-width PETHs time locked to receptacle entry were used for assessment of excitation or inhibition during receptacle entry. The existence of an excitatory or inhibitory response to each event (within the analysis time windows described in Table 1) was determined by the presence of at least three consecutive $0.1 \mathrm{~s}$ bins that showed higher or lower firing rate than the mean firing rate $+2 \mathrm{SD}$ (excitation) or $-2 \mathrm{SD}$ (inhibition) of the neuron during the $10 \mathrm{~s}$ pre-DS baseline. For inhibition, if the mean -2 SD was negative, the 
Table 1. Summary of analysis windows and results of bilateral injection of M/B

\begin{tabular}{|c|c|c|c|c|c|c|c|c|}
\hline \multirow[b]{2}{*}{ Neuronal response type } & \multirow[b]{2}{*}{ Analysis window } & \multirow[b]{2}{*}{$n$} & \multicolumn{3}{|c|}{ Basal firing rate } & \multicolumn{3}{|c|}{ Excitation or inhibition } \\
\hline & & & Pre $(\mathrm{Hz})$ & Post (Hz) & $p$ & Pre $(\mathrm{Hz})$ & Post (Hz) & $p$ \\
\hline \multicolumn{9}{|l|}{$25 \mathrm{ng}$ of $\mathrm{M} / \mathrm{B}$} \\
\hline Incentive cue excitation & $0-1$ s after DS & 11 & 2.5 & 3.0 & 0.19 & 2.9 & 1.2 & $<0.001$ \\
\hline Incentive cue inhibition & $0-1$ s after DS & 16 & 3.3 & 2.7 & 0.34 & 1.7 & 0.4 & $<0.05$ \\
\hline Operant excitation & $0-1$ s before lever press & 8 & 2.8 & 3.2 & 0.47 & 3.4 & 1.9 & $<0.05$ \\
\hline Operant inhibition & $0-1$ s before lever press & 11 & 2.6 & 2.3 & 0.52 & 1.6 & 1.0 & 0.08 \\
\hline Receptacle excitation & $0-5$ s after receptacle entry & 10 & 1.4 & 1.6 & 0.42 & 0.9 & 0.9 & 0.87 \\
\hline Receptacle inhibition & $0-5$ s after receptacle entry & 17 & 3.3 & 2.4 & 0.35 & 1.3 & 1.0 & 0.25 \\
\hline Receptacle exit excitation & $0-0.5$ s before and $0-1 \mathrm{~s}$ after receptacle exit & 6 & 2.7 & 2.6 & 0.98 & 2.8 & 1.0 & 0.08 \\
\hline \multicolumn{9}{|l|}{$50 \mathrm{ng}$ of $M / B$} \\
\hline Incentive cue excitation & $0-1$ s after DS & 9 & 2.6 & 2.3 & 0.17 & 2.8 & 1.0 & $<0.01$ \\
\hline Incentive cue inhibition & $0-1$ s after DS & 8 & 3.2 & 2.0 & 0.08 & 1.7 & 0.4 & $<0.01$ \\
\hline Operant excitation & $0-1$ s before lever press & 9 & 3.4 & 3.2 & 0.50 & 3.5 & 2.8 & 0.42 \\
\hline Operant inhibition & $0-1$ s before lever press & 8 & 2.3 & 2.3 & 0.99 & 1.3 & 0.4 & 0.25 \\
\hline Receptacle excitation & $0-5 \mathrm{~s}$ after receptacle entry & 11 & 1.3 & 1.4 & 0.85 & 0.6 & 0.6 & 0.63 \\
\hline Receptacle inhibition & $0-5$ s after receptacle entry & 17 & 3.2 & 2.6 & $<0.05$ & 1.1 & 0.9 & 0.18 \\
\hline Receptacle exit excitation & $0-0.5 \mathrm{~s}$ before and $0-1 \mathrm{~s}$ after receptacle exit & 7 & 2.8 & 2.9 & 0.85 & 3.0 & 1.8 & 0.15 \\
\hline
\end{tabular}

The analysis window is the section of PETH used to detect the bin matching to the criteria for excitation or inhibition. $n$ values are the numbers of neurons used to analyze the effects of dmPFC inactivation on the indicated response type. Baseline firing rate refers to the $10 \mathrm{~s}$ pre-DS baseline firing rate, which was averaged across all preinjection and postinjection DS presentations for each neuron. $p$ values are the results of $t$ test comparing basal firing rate (or excitation or inhibition) before and after $\mathrm{M} / \mathrm{B}$ injection. The first column of $p$ values shows the results of comparisons of baseline firing rate, and the second column of $p$ values shows the results of comparisons of excitations or inhibitions. Comparisons with a significant difference are indicated in bold.

criterion was at least four consecutive bins at lower firing rate than mean - SD. To be included in the incentive cue excited or inhibited category, at least one bin matching the criteria had to occur between 0 and $0.5 \mathrm{~s}$ after DS onset. Similarly, to be included in the operant excited or inhibited category, at least one bin matching the criteria had to occur within $0-0.5 \mathrm{~s}$ before the lever press. Furthermore, if neurons with operant inhibition also showed DS inhibition, they were removed from the operant-inhibited category. Similarly, if neurons with receptacle excitation or inhibition showed operant excitation or inhibition, they were excluded from the receptacle excited or inhibited category.

For each neuron, the magnitude of excitation related to incentive cue, operant response, and receptacle exit was computed by subtracting the average firing rate during the $10 \mathrm{~s}$ pre-DS baseline from the average firing rate of the consecutive bins that showed a higher rate than the mean +2 $\mathrm{SD}$ of the $10 \mathrm{~s}$ pre-DS baseline. The magnitude of inhibition for these events was computed by subtracting the averaged firing rate of consecutive bins showing a lower rate than the mean -2 SD or SD of the $10 \mathrm{~s}$ pre-DS baseline from the average firing rate during the $10 \mathrm{~s}$ pre-DS baseline. The magnitude of receptacle excitation was computed by subtracting the $10 \mathrm{~s}$ pre-DS baseline firing rate from the firing rate during $5 \mathrm{~s}$ after receptacle entry; the magnitude of receptacle inhibition was computed by subtracting the $5 \mathrm{~s}$ postreceptacle entry window from the $10 \mathrm{~s}$ pre-DS baseline. These calculations were made separately for preinjection and postinjection epochs. Mean firing increases or decreases and the average pre-DS baseline firing were compared across neurons between preinjection and postinjection conditions using the paired $t$ test.

Differences in all comparisons were considered significant at $p<0.05$.

Histology. At the end of experiments, animals were deeply anesthetized with sodium pentobarbital and perfused with saline and 10\% Formalin. Sections $(50 \mu \mathrm{m})$ including the $\mathrm{dmPFC}$ or NAc were cut on a cryostat and stained or immunostained with neutral red or anti-calbindin antibody at every other slice to determine the boundary of the core and shell of the NAc. Electrode placements were determined by passing a current through each electrode before perfusion to deposit iron at the tip and completing the perfusion with potassium ferrocyanide solution to develop the Prussian blue deposit. For animals with movable arrays, the deepest recording sites were marked by Prussian blue deposit, and the exact location of each recorded neuron was calculated by the distance from the deposit.

\section{Results}

Effects of bilateral dmPFC inactivation on behaviors

Figure 1 shows the behavioral effects of inactivation of the dmPFC during the DS task. M/B injected into the dmPFC dose-
A

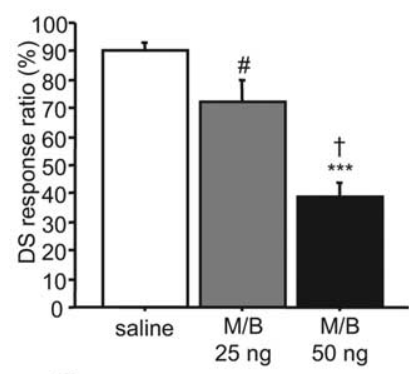

C

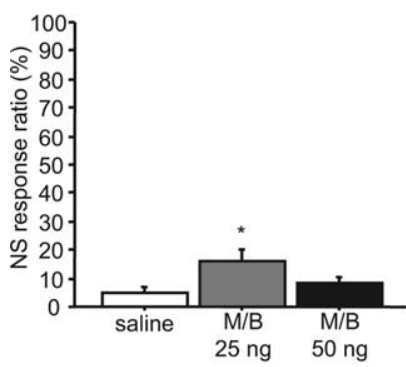

B

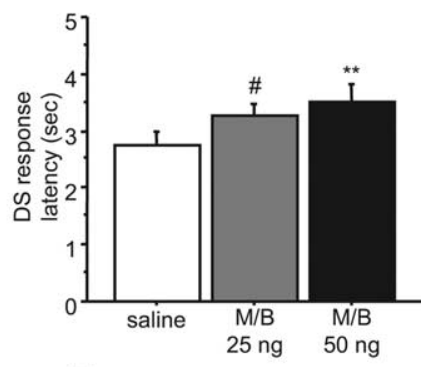

D

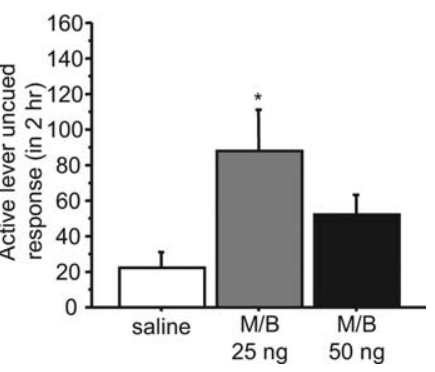

Figure 1. Inactivation of the $\mathrm{dm} P F C$ reduces behavioral responding to $D S S . A, B, M / B$ injection into the dmPFC dose-dependently reduces the DS response ratio $(\boldsymbol{A})$ and increases DS response latency $(\boldsymbol{B}) . \boldsymbol{C}, \boldsymbol{D}, \mathrm{M} / \mathrm{B}(25 \mathrm{ng})$ injected into the $\mathrm{dm} P F C$ also increased $N S$ response ratio (C) and uncued active lever responses (D). ${ }^{\#} p<0.05,{ }^{*} p<0.01,{ }^{* *} p<0.001,{ }^{* * *} p<0.0001$ compared with the saline group; ${ }^{\dagger} p<0.05$ compared with $25 \mathrm{ng}$ of M/B. In this and subsequent figures, error bars represent SEM.

dependently reduced the proportion of DSs to which the animals responded with a lever press $\left(F_{(2,16)}=28.35 ; p<0.0001\right)$ (Fig. $1 A)$ and increased DS response latency $\left(F_{(2,16)}=9.71 ; p<0.01\right)$ (Fig. $1 B$ ). Both NS response ratio and uncued responding on the active lever were augmented by injection of $25 \mathrm{ng} \mathrm{M} / \mathrm{B}$ injection, although $50 \mathrm{ng}$ of $\mathrm{M} / \mathrm{B}$ had no significant effects on these measures (NS response ratio, $F_{(2,16)}=6.75, p<0.01$; active lever uncued response, $F_{(2,16)}=6.82, p<0.01$ ) (Fig. 1C,D). Consistent with our previous study (Ishikawa et al., 2007), these results indicate that the $\mathrm{dmPFC}$ is required for behavioral responding to reward-predictive cues during the DS task. 

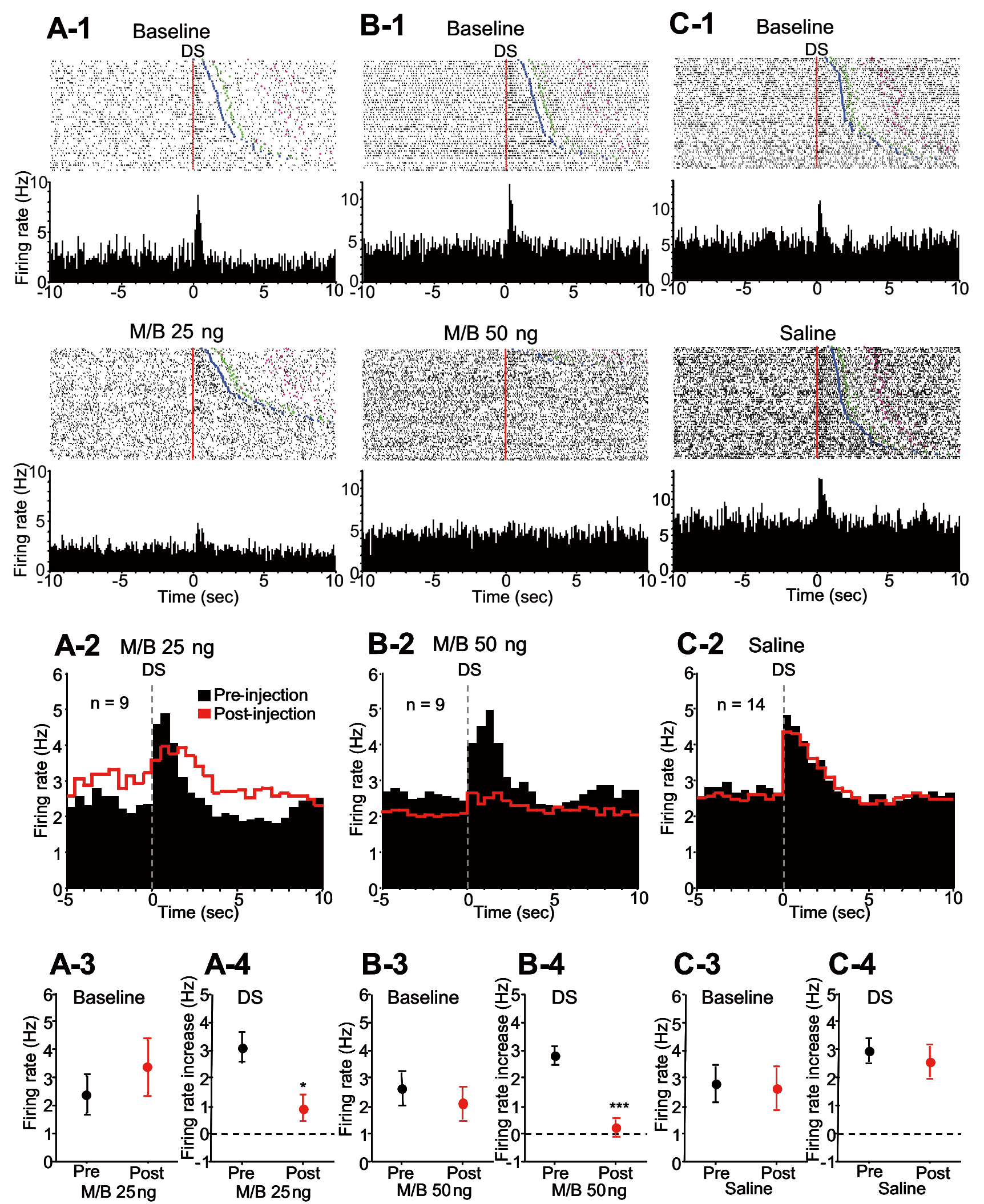

Figure 2. Inactivation of the dmPFC reduces the DS-evoked excitation of NAc neurons. A-1, B-1, C-1, Raster plots and PETH (0.1 s bin width) examples of different incentive cue-excited neurons before (top) and after (bottom) $25 \mathrm{ng}$ of M/B, $50 \mathrm{ng}$ of M/B, and saline injection, respectively. Neurons in $\boldsymbol{A}-\mathbf{B}$ and $\boldsymbol{B}-\mathbf{1}$ were recorded from distinct electrodes in the same animal in different sessions, and the neuron in $\mathbf{C}-\mathbf{1}$ was recorded from a different animal. The rasters are time locked to DS presentation (red line) and sorted by latency to respond to the DS. Injections of 25 and $50 \mathrm{ng}$ of M/B into the $\mathrm{dmPFC}$ reduce the DS-evoked excitation of these neurons, whereas saline injection has no effect. Blue points indicate the time of operant response, and greenand pink points show the reward receptacle entry and exit. $A-2, B-2, C-2$, Averaged PETHs ( $0.5 \mathrm{~s}$ bin width) of pooled DS-excited neurons before (black) and after (red) $25 \mathrm{ng}$ of $\mathrm{M} / \mathrm{B}, 50$ $\mathrm{ng}$ of $\mathrm{M} / \mathrm{B}$, and saline injections, respectively. Histograms are all time locked to DS presentation. $A-3, B-3, C-3$, Comparisons of baseline firing rates of DS-excited neurons before (black) and after (red) each drug injection. $A-4, B-4, C-4$, Comparisons of DS-evoked excitations before and after each drug injection. ${ }^{*} p<0.01,{ }^{* * *} p<0.0001$ compared with the data of the same neurons in the preinjection epoch 

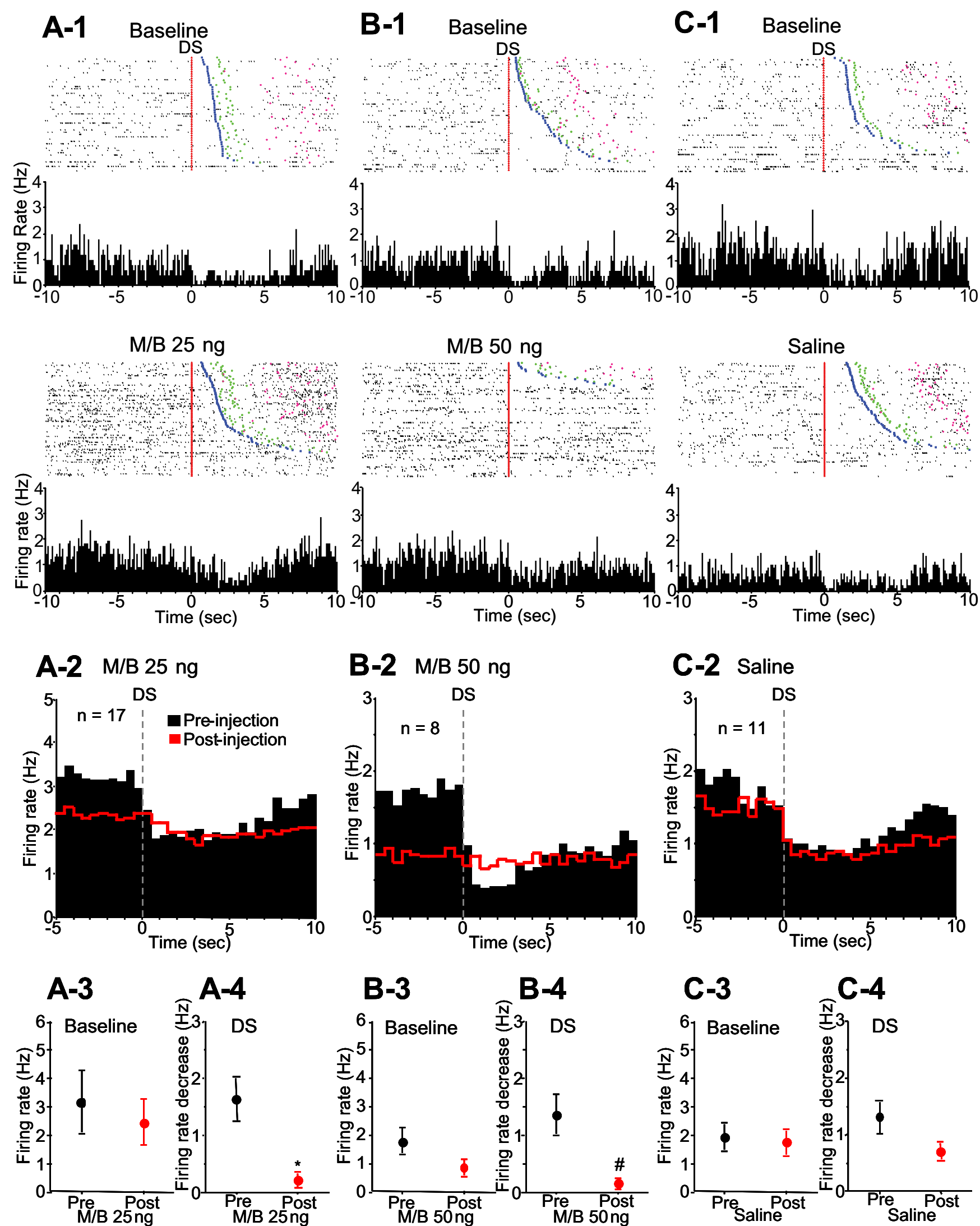

Figure 3. Inactivation of the dmPFC reduces the DS-evoked inhibition of NAc neurons. $\boldsymbol{A}-\mathbf{1}, \boldsymbol{B}-\mathbf{1}, \boldsymbol{C}-\mathbf{1}$, Raster plots and PETHs (0.1 s bin width) examples of different incentive cue-inhibited neurons before (top) and after (bottom) $25 \mathrm{ng}$ of M/B, $50 \mathrm{ng}$ of M/B, and saline injection, respectively. These neurons were recorded from different animals. The rasters are time locked to DS presentation (red line). Injections of 25 and $50 \mathrm{ng}$ of M/B into the dmPFC reduce the DS-evoked inhibition of these neurons, whereas saline injection has no effect on the firing. Blue, green, and pink points show the same events as in Figure 2. A-2, B-2, C-2, Averaged PETHs ( $0.5 \mathrm{~s}$ bin width) of DS-inhibited neurons before (black) and after (red) $25 \mathrm{ng}$ of $M / B, 50 \mathrm{ng}$ of $M / B$, and saline injections, respectively. Histograms are all time locked to DS presentation. $\boldsymbol{A}-\mathbf{3}, \boldsymbol{B}-\mathbf{3}, \mathbf{C}-\mathbf{3}$, Comparisons of baseline firing rates of DS-inhibited neurons before (black) and after (red) each drug injection. $\boldsymbol{A}-\mathbf{4}$, $B-4, C-4$, Comparisons of DS-evoked inhibitions before and after each drug injection. ${ }^{\#} p<0.05,{ }^{*} p<0.01$ compared with the preinjection epoch. 


\section{Effects of bilateral dmPFC inactivation on NAc neuronal firing}

Incentive cue excitations and inhibitions

Incentive cue excitations began almost immediately after DS presentation. As shown in the example in Figure 2, $A-1$ and $B-1$, bilateral $\mathrm{M} / \mathrm{B}$ injections that reduced the DS response ratio profoundly reduced the DS-evoked excitatory firing of NAc neurons, whereas saline injection did not affect the incentive cue excitation (Fig. 2C-1). The effects of M/B (25 or $50 \mathrm{ng}$ ) and saline injection into the dmPFC on incentive cue-excited neurons are summarized across recorded neurons in Figure 2, $A-2, B-2$, and $C-2$. Injection of $25 \mathrm{ng}$ of $\mathrm{M} / \mathrm{B}$ into the $\mathrm{dmPFC}$ caused a trend toward an increase in the average baseline firing rate (Fig. 2A-3) and significantly reduced the mean DS-evoked excitation (Fig. 2A4). After $50 \mathrm{ng} \mathrm{M} / \mathrm{B}$ injection, baseline firing rates trended toward a reduction (Fig. $2 \mathrm{~B}-3$ ), and DS excitation was significantly reduced (Fig. 2 B-4). In contrast, in the 14 neurons recorded before and after saline injection, no significant effects on either baseline firing rate or DS-evoked excitation were observed (Fig. 2C-3,C-4).

Similar to incentive cue excitations, incentive cue inhibitions began immediately after $\mathrm{DS}$ onset. $\mathrm{M} / \mathrm{B}$ injection into the $\mathrm{dmPFC}$ profoundly reduced DS-evoked inhibition of NAc neurons (Fig. $3 A-1, B-1$ ), whereas saline injection had no effect (Fig. 3C-1). Injection of either $25 \mathrm{ng}$ (Fig. $3 A-2, A-3)(n=17)$ or $50 \mathrm{ng}$ (Fig. $3 B-2, B-3)(n=8) \mathrm{M} / \mathrm{B}$ caused a trend toward reduction in baseline firing rate, whereas the magnitude of the cue-evoked inhibition was significantly reduced (Fig. $3 A-2, A-4, B-2, B-4$ ). In contrast, injection of saline into the $\mathrm{dmPFC}$ had no significant effects on either baseline firing rate or DS-evoked inhibition (Fig. $3 C$ $2, C-3, C-4)(n=11)$.

The major behavioral effect of dmPFC inactivation was a reduction in responding to the DS (Fig. $1 A$ ). Both incentive cue excitations and inhibitions are smaller when the animal fails to make a behavioral response to the DS than when the animal makes an appropriate operant response (Nicola et al., 2004b). To determine whether the reduction in incentive cue excitation and inhibition caused by dmPFC inactivation was entirely dependent on the reduction in behavioral responding to the DS, we examined the excitations and inhibitions evoked by DSs to which the animal responded with a lever press. (This analysis therefore excludes the majority of postinjection DSs, to which the animal did not respond.) Averaged histograms constructed from DS-excited neurons recorded before and after bilateral $25(n=11)$ or $50(n=$ 9) ng M/B injection show that the postinjection DS-evoked excitation was smaller than the preinjection excitation (Fig. $4 A, B$; Table 1), whereas baseline firing rate tended to increase ( $25 \mathrm{ng}$ ) or decrease (50 ng) after injection (Table 1). DS-evoked inhibitions recorded before and after $25(n=16)$ or $50(n=8) \mathrm{ng} \mathrm{M} / \mathrm{B}$ injection were also significantly reduced (Fig. $4 C, D$; Table 1). Thus, the reduction of incentive cue excitation and inhibition caused by dmPFC inactivation cannot simply be secondary to the reduction in behavioral cue responding. These results suggest that the reduction of incentive cue excitation and inhibition after $\mathrm{dmPFC}$ inactivation is at least in part responsible for the reduction in behavioral responding to the DS.

\section{Operant, reward-associated, and receptacle exit excitations} and inhibitions

We determined whether dmPFC inactivation affected NAc neuronal firing related to task events other than DS presentation, including operant response, reward consumption, and receptacle exit. Figure 5 shows averaged histograms and comparisons of
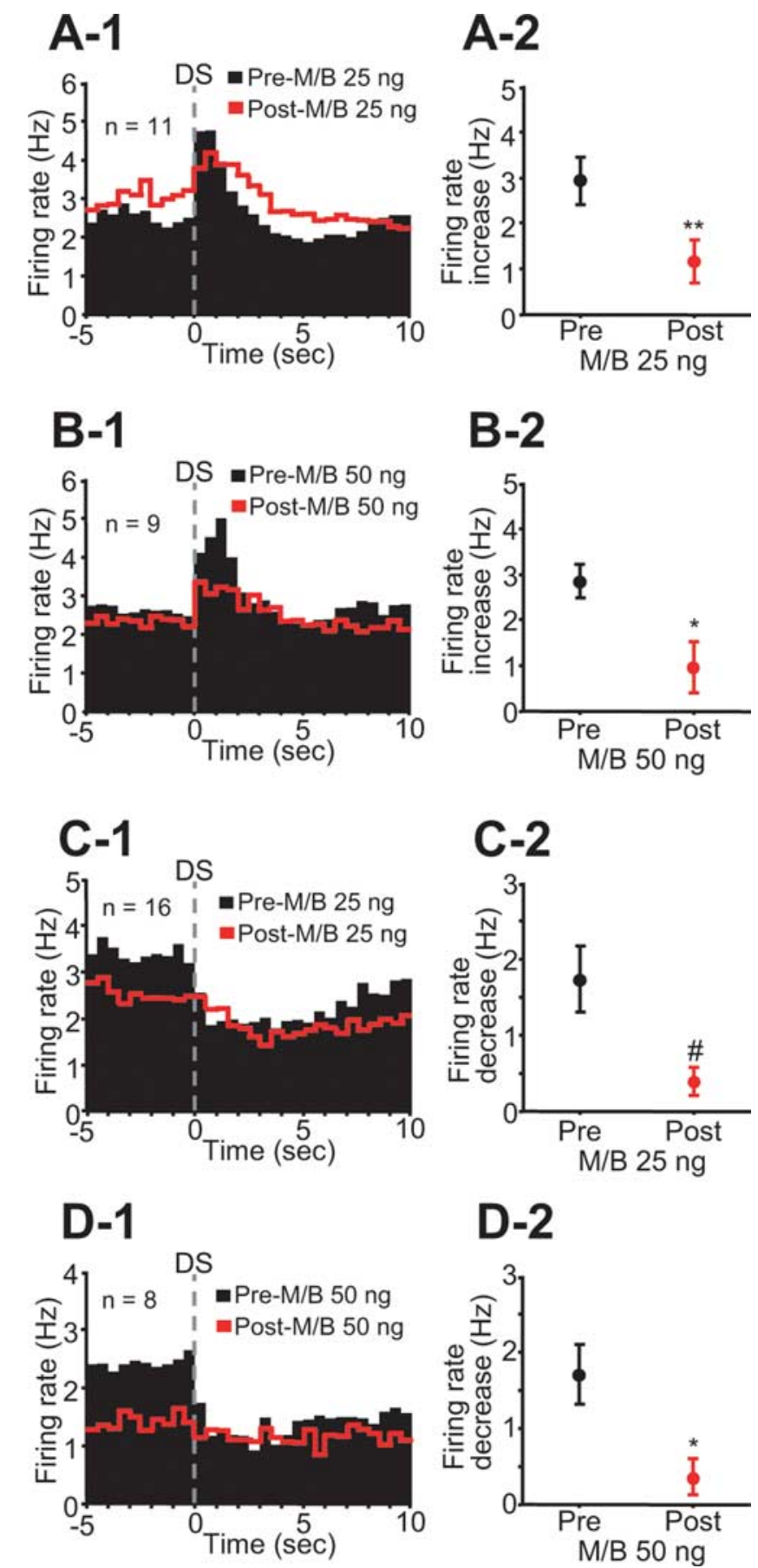

Figure 4. Inactivation of the $\mathrm{dmPFC}$ reduces incentive cue excitation and inhibition on trials when the animal makes a behavioral response to the DS. $\boldsymbol{A} \mathbf{- 1}, \boldsymbol{B}-\mathbf{1}$, Averaged PETHs $(0.5 \mathrm{~s}$ bin width) of DS-excited neurons before (black) and after (red) 25 and $50 \mathrm{ng} \mathrm{M/B}$ injections. A-2, $B-2$, Comparisons of DS excitation between preinjection and postinjection of each drug. C-1, $D-1$, Averaged PETHs ( $0.5 \mathrm{~s}$ bin width) of DS-inhibited neurons before and after each drug injection. C-2, D-2, Comparisons of DS inhibition between preinjection and postinjection. ${ }^{\#} p<$ $0.05,{ }^{*} p<0.01,{ }^{* *} p<0.001$ compared with the preinjection epoch.

firing rate changes indicating that the magnitude of operant excitation and inhibition, receptacle excitation and inhibition (which occur during reward consumption), and receptacle exit excitation were all unaffected by dmPFC inactivation, except for a slight reduction of operant excitation induced by $25 \mathrm{ng} \mathrm{M} / \mathrm{B}$ injection (Table 1). The basal firing rate of these neurons was not changed except for a significant decrease after $50 \mathrm{ng} \mathrm{M} / \mathrm{B}$ injection in neurons with receptacle inhibition (Table 1). 
Correlation of NAc neuronal firing with behavioral cue responding dmPFC inactivation that impaired behavioral responding to DSs reduced DSevoked excitation or inhibition of NAc core neurons. These findings suggest that either the DS excitation or inhibition or both are required for appropriate cue responding. To further examine the relationship between NAc neuronal firing and the behavioral deficit, we regressed DS-evoked excitation or inhibition against DS response ratio in the postinjection session (Fig. 6). To obtain each data point, the magnitudes of DS excitations or inhibitions were averaged across neurons recorded in each session; data were obtained from $25 \mathrm{ng}$ of $\mathrm{M} / \mathrm{B}$, $50 \mathrm{ng}$ of $\mathrm{M} / \mathrm{B}$, and saline injection sessions. The DS response ratio was significantly correlated with the magnitude of DS excitation but not DS inhibition (Fig. $6 A, B)$. Furthermore, there was a significant negative correlation between DS excitation and DS response latency (Fig. 6C). These findings suggest that the attenuation of incentive cue excitation of NAc core neurons resulting from dmPFC inactivation impairs behavioral responses to the cue.

Effects of unilateral dmPFC inactivation on behavior and NAc neuronal firing Direct dmPFC projections to the NAc core are predominantly ipsilateral. To investigate the effects of unilateral dmPFC inactivation on cue responding, we recorded from NAc core neurons before and after unilateral microinjection of $\mathrm{M} / \mathrm{B}$ into the dmPFC. The behavioral effects of unilateral dmPFC inactivation were less pronounced than those of bilateral inactivation. Injection of $50 \mathrm{ng}$ of $\mathrm{M} / \mathrm{B}$ significantly reduced the DS response ratio (Fig. $7 A$ ), but $25 \mathrm{ng}$ of M/B had no effect on any behavioral measure (Fig. 7A-D). As for the effects of unilateral dmPFC inactivation on NAc neuronal firing, injection of $25 \mathrm{ng}$ of $\mathrm{M} / \mathrm{B}$ into the dmPFC did not affect DS-evoked excitation or inhibition of ipsilateral or contralateral neurons (ipsilateral DSexcited neurons: $n=9, p=0.52$; contralateral DS-excited neurons: $n=9, p=0.60$; ipsilateral DS-inhibited neurons: $n=6, p=$ 0.23 ; contralateral DS-inhibited neurons: $n=6, p=0.58$ ). However, $50 \mathrm{ng} \mathrm{M} / \mathrm{B}$ injection significantly reduced DS excitations of ipsilateral but not contralateral NAc core neurons (Fig. 7E,F), whereas DS inhibitions of contralateral but not ipsilateral neurons were significantly attenuated by $50 \mathrm{ng}$ of M/B (Fig. 7G,H). In both ipsilateral and contralateral sides, the basal firing rates of DS-excited and -inhibited neurons were not affected by $50 \mathrm{ng}$ of $\mathrm{M} / \mathrm{B}$ injected into the $\mathrm{dmPFC}$ (ipsilateral DS-excited neurons, $p=0.73$; contralateral DS-excited neurons, $p=0.93$; ipsilateral DS-inhibited neurons, $p=0.29$; contralateral DS-inhibited neurons, $p=0.22$ ). Together with our other findings, these results are most consistent with the idea that an ipsilateral excitatory

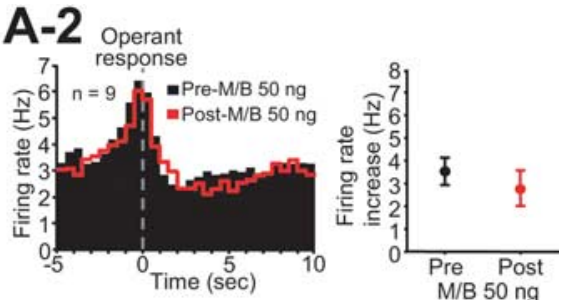

\section{B-2 Operant}
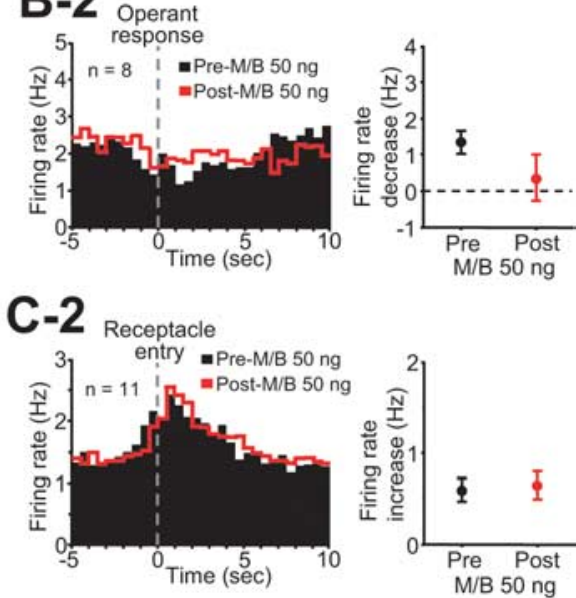

$D-2_{\text {Reeopalace }}$
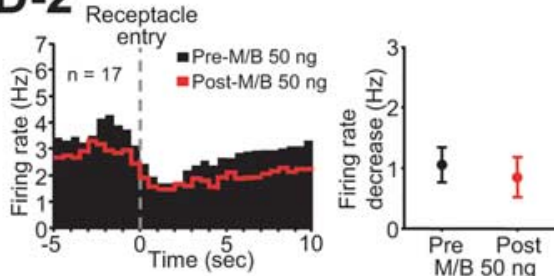

$\mathrm{E}-\mathbf{2}_{\text {Recopatacle }}$
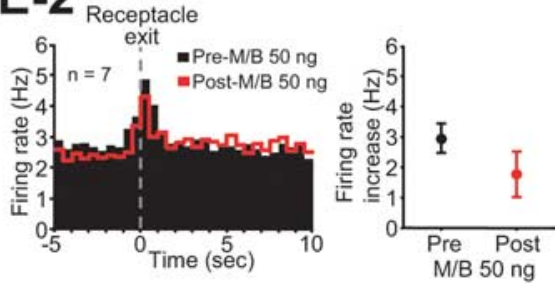

Figure 5. Inactivation of the dmPFC does not affect operant, reward-related, and receptacle exit neuronal firing except for a small effect of $25 \mathrm{ng}$ of $\mathrm{M} / \boldsymbol{B}$ on operant excitations. $\boldsymbol{A}-\mathbf{1}-\boldsymbol{E}-\mathbf{2}$, Each left panel shows averaged PETHs ( $0.5 \mathrm{~s}$ bin width) time locked to the operant response $(\boldsymbol{A}-\mathbf{1}, \boldsymbol{A}-\mathbf{2}, \boldsymbol{B}-\mathbf{1}, \boldsymbol{B}-\mathbf{2})$, receptacle entry $(\boldsymbol{C}-\mathbf{1}, \boldsymbol{C}-\mathbf{2}, \mathbf{D}-\mathbf{1}, \boldsymbol{D}-\mathbf{2})$, and exit $(\boldsymbol{E}-\mathbf{1}, \boldsymbol{E}-\mathbf{2})$, and each right panel shows comparisons of each firing response before and after drug injection. ${ }^{\#} p<0.05$ compared with preinjection.

projection from the dmPFC to the NAc is essential for appropriate cue responding. There may also be a contribution to incentive cue responding for the contralateral inhibitory effect, but this is less clear.

Histological verification of electrode and cannula placements The tips of microinjection cannulas used for $\mathrm{dmPFC}$ inactivation were all within the $\mathrm{dmPFC}$, in the prelimbic or cingulate cortex (Fig. $8 A$ ). The recording electrode sites located within the core of the NAc were plotted on the rat brain atlas (Fig. $8 B$ ) (Paxinos and Watson, 1998). A few electrodes were outside of the core; neurons recorded from those electrodes were excluded from the analysis.

\section{Discussion}

Microinjection of $\mathrm{GABA}_{\mathrm{A}}$ and $\mathrm{GABA}_{\mathrm{B}}$ agonists $(\mathrm{M} / \mathrm{B})$ into the $\mathrm{dmPFC}$ substantially reduced operant behaviors in response to 
A DS (+) magnitude

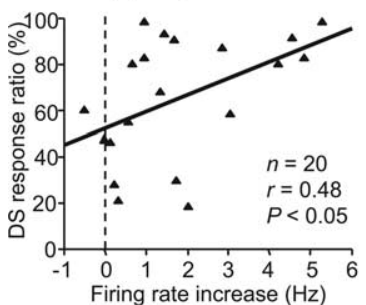

B DS (-) magnitude

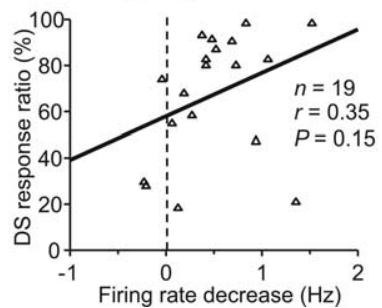

$\mathbf{C}_{\text {DS (+) latency }}$

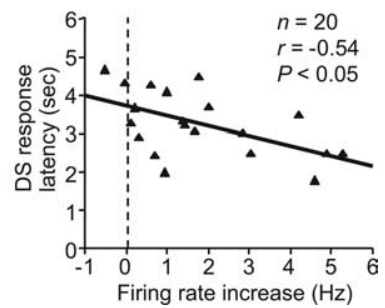

Figure 6. Correlation of DS responding behavior with neuronal firing to DSs. $A, B$, The DS response ratio was significantly correlated with DS excitation $(\boldsymbol{A})$ but not inhibition $(\boldsymbol{B})$ after injection of $25 \mathrm{ng}$ of $M / B, 50 \mathrm{ng}$ of $M / B$, and saline (3 conditions pooled). $C$, There was significant negative correlation between DS response latency and DS excitation in the postinjection period.
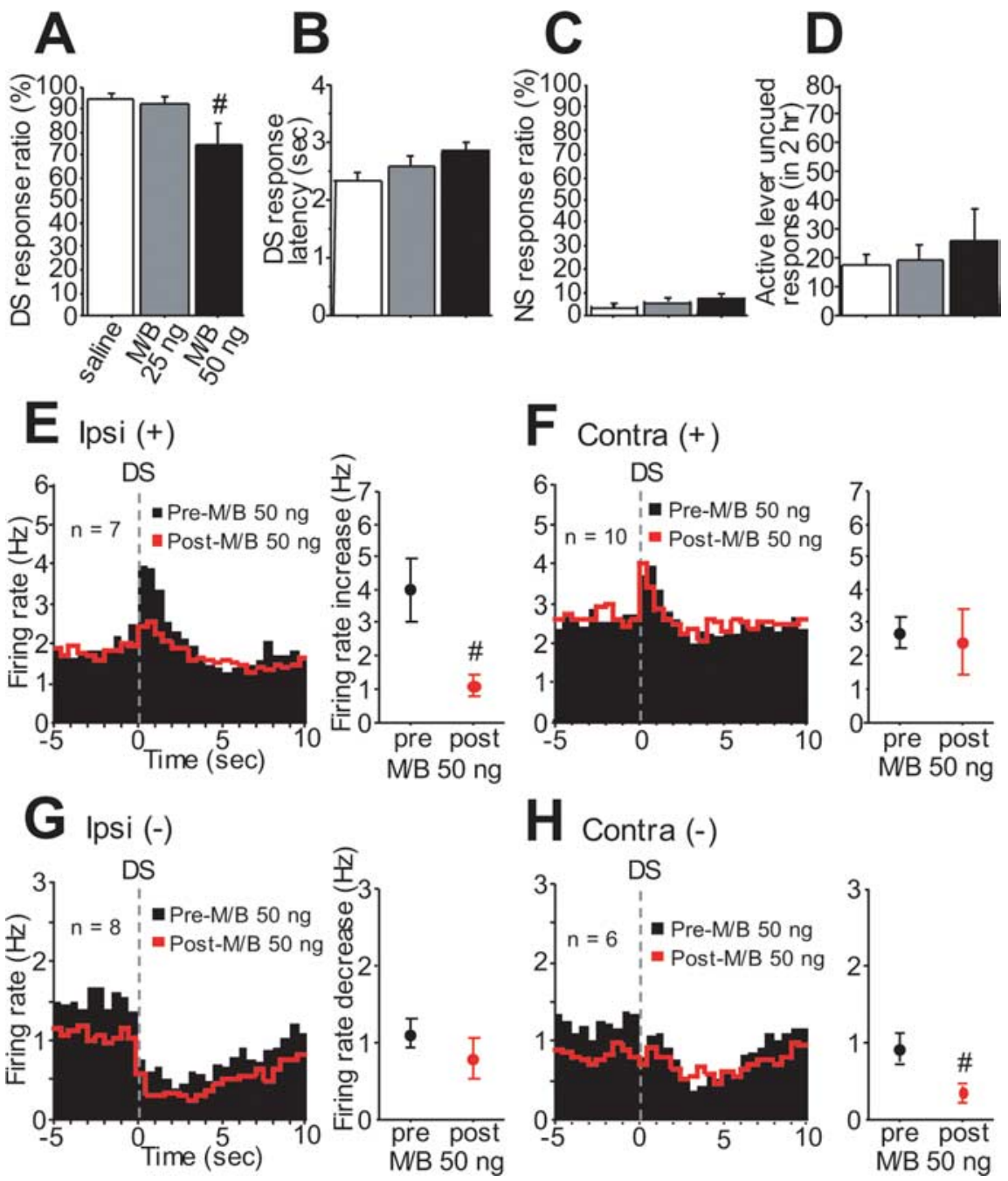

Figure 7. Unilateral dmPFC inactivation reduces DS responding and both ipsilateral DS excitation and contralateral DS inhibition. $\boldsymbol{A}-\boldsymbol{D}, \mathrm{M} / \mathrm{B}(50 \mathrm{ng})$ injected into the dmPFC reduces DS response ratio $(\boldsymbol{A})$ without affecting DS response latency $(\boldsymbol{B})$, NS response ratio $(\boldsymbol{C})$, or uncued responding $(\boldsymbol{D}) . \boldsymbol{E}, \boldsymbol{F}$, Unilateral injection of $50 \mathrm{ng}$ of $\mathrm{M} / \mathrm{B}$ reduces ipsilateral $(\boldsymbol{E})$ but not contralateral $(\boldsymbol{F})$ DS excitation. $\mathbf{G}, \boldsymbol{H}$, In contrast, contralateral $(\boldsymbol{H})$ but not ipsilateral $(\boldsymbol{G})$ DS inhibition is attenuated after $50 \mathrm{ng} M / B$ injection.

ronal firing (Yun et al., 2004b) and that both VTA inactivation and injection of dopamine antagonists into the NAc reduced the reward-seeking behavioral response to cues (Yun et al., 2004a,b). Because dopamine alone does not directly excite NAc neurons (Nicola et al., 2000, 2004a), it is likely that dopamine enhances incentive cue responses by facilitating glutamatemediated excitatory inputs arising from afferents to the NAc. The present work suggests that neurons in the dmPFC are a significant source of the excitatory afferents underlying the NAc dopaminedependent cue responses.

We showed previously that VTA inactivation reduces not only NAc excitations and inhibitions evoked by the DS but also the baseline firing rate of DS-excited and -inhibited neurons (Yun et al., 2004b). This result raised the possibility that the tonic firing of these neurons, rather than the cue-evoked phasic firing, is permissive for the cue response. In the present study, dmPFC inactivation only minimally affected the baseline firing rate of NAc neurons but profoundly reduced phasic excitations and inhibitions. Because these were the only substantial effects of dmPFC inactivation on the firing of NAc neurons and because bilateral inactivation of the $\mathrm{dmPFC}$ reduces the behavioral response to cues, our results argue that it is the phasic, cue-evoked excitation and inhibition of NAc neurons (and not their tonic firing) that drives the behavioral response to cues.

This interpretation is further supported by findings that the magnitude of the cueevoked excitation after dmPFC inactivation correlates positively with the probability that the animal will respond and correlates negatively with the response latency (Fig. 6). Such correlations would also be expected if the cue-evoked firing tracked reward-seeking behavior rather than causing it. However, cue-evoked excitations were reduced by dmPFC inactivation even on the few trials in which the animals made an operant response (Fig. 4), indicating that the changes in evoked firing observed after dmPFC inactivation is not secondary to the behavioral change. Furthermore, unilateral inactivation of the dmPFC with $50 \mathrm{ng}$ of $\mathrm{M} / \mathrm{B}$ reduced ipsilateral NAc core DS-evoked excitations to the same degree reward-predictive cues during the DS task. Inactivation of the dmPFC also substantially reduced the magnitude of the DSevoked excitatory and inhibitory neuronal responses but had minimal, if any, effects on the baseline firing rate or on firing associated with other task events. In previous work, we found that inactivation of the VTA in animals performing a similar DS task also selectively reduced the magnitude of cue-evoked NAc neu- as bilateral dmPFC inactivation, despite the fact that the behavvation was much less pronounced. Similarly, unilateral dmPFC inactivation was just as effective at reducing DS-evoked inhibitions in the contralateral NAc as bilateral inactivation. These results are inconsistent with the hypothesis that cue-evoked excitations in the NAc are a consequence of cue responding behavior ioral impairment in cue responding caused by unilateral inacti- 
generated by other circuits and in fact argue strongly that ipsilateral projections from the dmPFC to the NAc core drive cue-evoked excitations that are required for the reward-seeking behavioral response.

Although the present results strongly implicate dmPFC to NAc core projections in NAc neuronal and behavioral responding to cues, they do not prove that the necessary projection is direct (monosynaptic). In the case of DS-evoked inhibitions, because the direct dmPFC projection to the NAc is glutamatergic (Pennartz et al., 1994; O’Donnell and Grace, 1995; Zahm, 2000), it is likely that the projection responsible for the inhibitions is indirect. Another possibility, that the DS-evoked inhibitions are attributable to a cue-evoked reduction in firing of dmPFC neurons that excite NAc neurons, can be ruled out because the base-

line firing rate of NAc cue-inhibited neurons did not decrease substantially when the dmPFC was inactivated. In the case of NAc DS-evoked excitations, the existence of a direct, predominantly ipsilateral (Sesack et al., 1989; Berendse et al., 1992) excitatory dmPFC-NAc core projection supports the hypothesis that this direct projection underlies the NAc core excitations. Furthermore, single NAc neurons receive convergent input from the mPFC and VTA (Sesack and Pickel, 1992). This is consistent with the reduction in excitation of this class of neurons by both dmPFC and VTA inactivation, which is potentially the result of several mechanisms by which dopamine can facilitate the excitation of NAc neurons (Nicola et al., 2000, 2004a; Hopf et al., 2003; Hjelmstad, 2004; Fields et al., 2007).

An alternative hypothesis is that the NAc core DS-evoked excitations arise from a projection between the $\mathrm{dmPFC}$ and the BLA (Cardinal et al., 2002; Schoenbaum et al., 2003; Saddoris et al., 2005). BLA neurons also excite NAc core neurons (Johnson et al., 1994; O'Donnell and Grace, 1995; Mulder et al., 1998), and indeed the BLA to NAc core projection is essential for both rewardseeking behavior in response to the DS and the NAc neuronal firing response to cues (Ambroggi et al., 2007). However, most NAc neurons that receive excitation from the BLA also receive excitation from the PFC (O'Donnell and Grace, 1995), and the BLA input serves to gate excitation from the PFC (Goto and O'Donnell, 2002), consistent with the hypothesis that direct input from both structures (as well as the VTA) is required for robust activation of NAc core neurons by reward-predictive cues.

Interestingly, the baseline firing rate of NAc DS-excited neurons showed a trend toward an increase when the lowest (25 ng) dose of $\mathrm{M} / \mathrm{B}$ was injected in the $\mathrm{dmPFC}$. The behavioral effects of this injection were qualitatively different from higher dose injection as well: responding to the NS and responding in the absence of cues were increased (Fig. 1). These results are similar to those after inactivation of the ventral mPFC (primarily infralimbic cortex) (Ishikawa et al., 2007), suggesting that the behavioral disinhibition is attributable to the action of drugs on ventral mPFC. Consistent with this hypothesis, lesions of the ventral mPFC have been shown to disinhibit learned cue-directed behaviors in several contexts (Quirk et al., 2000; Passetti et al., 2002; Peters et al., 2008). Arguing against this hypothesis, however, is the finding that low, rather than high, doses of M/B injected into the dmPFC produce effects similar to those of ventral $\mathrm{mPFC}$ inactivation,
B

\section{NAc recording electrodes}

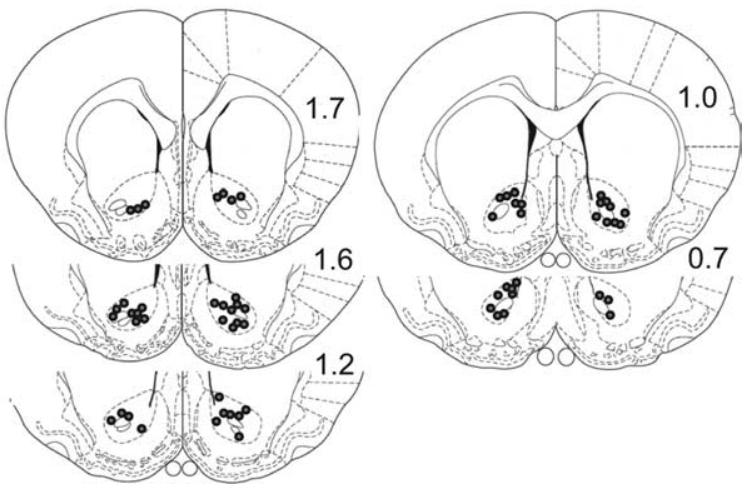

S. $B$ Diagram shows the locations of each tip of electrodes from which NAc core neurons were recorded. Diagrams are adapted from

despite the fact that drugs would be expected to diffuse dorsally up the cannula track rather than ventrally. We favor the hypothesis that the neurons that inhibit behavior are more concentrated in the ventral $\mathrm{mPFC}$ but are also present, although in smaller numbers, more dorsally in the prelimbic cortex. The behaviorinhibitory neurons may be more susceptible to inhibition by $\mathrm{M} / \mathrm{B}$ attributable to higher numbers of $\mathrm{GABA}_{\mathrm{A}}$ or $\mathrm{GABA}_{\mathrm{B}}$ receptors. One possibility is that the behavior-inhibitory neurons are interneurons that inhibit subsets of behavior-excitatory neurons in the same region. This possibility is supported by the observation that, in certain brain regions, interneurons are more susceptible to inhibition via $\mathrm{GABA}_{\mathrm{A}}$ receptors than projection neurons (Xi and Stein, 1998; Doherty and Gratton, 2007).

The projection from the dmPFC to the core of the NAc is thought to play a pivotal role in the reinstatement of drug-seeking behavior by cues associated with drug reward (McFarland and Kalivas, 2001). Although we did not examine reinstatement, our results are consistent with this literature, and extend the importance of this projection to cue-evoked natural reward-seeking behavior. Furthermore, we have identified a population of neurons in the NAc core that is excited by reward-predictive cues and demonstrated that these neuronal responses depend on both VTA (presumably dopaminergic) and dmPFC projections. An intriguing hypothesis is therefore that these DS-responsive neurons underlie cue-evoked relapse to drug-seeking behavior. Additional studies should focus on this specific neuronal population to determine how they influence drug seeking and relapse.

In summary, we demonstrate that the projection from $\mathrm{dmPFC}$ to the NAc core is required for NAc neurons to fire maximally in response to reward-predictive cues presented during an operant task and that the dmPFC promotes the rewardseeking behavioral response to these cues. Because the BLA, the VTA, and dopamine receptor activation within the NAc are also required, our results suggest a simple circuit model, consistent with one that we proposed previously (Yun et al., 2004a; Nicola, 2007). When a reward-predictive cue is presented, glutamatergic neurons in the dmPFC (Takenouchi et al., 1999; Jodo et al., 2000) and BLA (Muramoto et al., 1993; Schoenbaum et al., 1998, 1999) are excited and release glutamate onto subpopulations of NAc neurons. Dopaminergic neurons in the VTA are excited as well (Ljungberg et al., 1992; Schultz et al., 1993; Pan et al., 2005) and release dopamine in the NAc core (Bassareo and Di Chiara, 1999; 
Ito et al., 2000; Weiss et al., 2000; Roitman et al., 2004; Day et al., 2007). Neurons in the BLA signal that an event of potential emotional significance is occurring (Hatfield et al., 1996; Blundell et al., 2001; Baxter and Murray, 2002), and dopaminergic neurons signal that a reward-predictive cue is being encountered (Schultz, 1998). The excited dmPFC neurons signal the action to be selected to obtain the reward (Passetti et al., 2002; Heidbreder and Groenewegen, 2003). When all of these inputs converge in the NAc core, just those neurons that receive convergent input from the cue-excited neurons in the afferent structures fire, increasing the probability of the specific behavioral response necessary to obtain reward.

\section{References}

Ambroggi F, Ishikawa A, Seroussi A, Fields HL, Nicola SM (2007) Evidence that dopamine enhance nucleus accumbens responses to incentive cues by gating an excitatory input from the basolateral amygdala. Soc Neurosci Abstr 33:310.8

Bassareo V, Di Chiara G (1999) Differential responsiveness of dopamine transmission to food-stimuli in nucleus accumbens shell/core compartments. Neuroscience 89:637-641.

Baxter MG, Murray EA (2002) The amygdala and reward. Nat Rev Neurosci 3:563-573.

Berendse HW, Galis-de Graaf Y, Groenewegen HJ (1992) Topographical organization and relationship with ventral striatal compartments of prefrontal corticostriatal projections in the rat. J Comp Neurol 316:314-347.

Blundell P, Hall G, Killcross S (2001) Lesions of the basolateral amygdala disrupt selective aspects of reinforcer representation in rats. J Neurosci 21:9018-9026.

Brog JS, Salyapongse A, Deutch AY, Zahm DS (1993) The patterns of afferent innervation of the core and shell in the "accumbens" part of the rat ventral striatum: immunohistochemical detection of retrogradely transported fluoro-gold. J Comp Neurol 338:255-278.

Cardinal RN, Parkinson JA, Hall J, Everitt BJ (2002) Emotion and motivation: the role of the amygdala, ventral striatum, and prefrontal cortex. Neurosci Biobehav Rev 26:321-352.

Day JJ, Wheeler RA, Roitman MF, Carelli RM (2006) Nucleus accumbens neurons encode Pavlovian approach behaviors: evidence from an autoshaping paradigm. Eur J Neurosci 23:1341-1351.

Day JJ, Roitman MF, Wightman RM, Carelli RM (2007) Associative learning mediates dynamic shifts in dopamine signaling in the nucleus accumbens. Nat Neurosci 10:1020-1028.

Doherty M, Gratton A (2007) Differential involvement of ventral tegmental $\mathrm{GABA}(\mathrm{A})$ and $\mathrm{GABA}(\mathrm{B})$ receptors in the regulation of the nucleus accumbens dopamine response to stress. Brain Res 1150:62-68.

Fields HL, Hjelmstad GO, Margolis EB, Nicola SM (2007) Ventral tegmental area neurons in learned appetitive behavior and positive reinforcement. Annu Rev Neurosci 30:289-316.

Ghitza UE, Fabbricatore AT, Prokopenko V, Pawlak AP, West MO (2003) Persistent cue-evoked activity of accumbens neurons after prolonged abstinence from self-administered cocaine. J Neurosci 23:7239-7245.

Goto Y, O'Donnell P (2002) Timing-dependent limbic-motor synaptic integration in the nucleus accumbens. Proc Natl Acad Sci USA 99:13189-13193.

Hatfield T, Han JS, Conley M, Gallagher M, Holland P (1996) Neurotoxic lesions of basolateral, but not central, amygdala interfere with Pavlovian second-order conditioning and reinforcer devaluation effects. J Neurosci 16:5256-5265.

Heidbreder CA, Groenewegen HJ (2003) The prefrontal cortex in the rat: evidence for a dorso-ventral distinction based upon functional and anatomical characteristics. Neurosci Biobehav Rev 27:555-579.

Hjelmstad GO (2004) Dopamine excites nucleus accumbens neurons through the differential modulation of glutamate and GABA release. J Neurosci 24:8621-8628.

Hopf FW, Cascini MG, Gordon AS, Diamond I, Bonci A (2003) Cooperative Activation of dopamine $\mathrm{D}_{1}$ and $\mathrm{D}_{2}$ receptors increases spike firing of nucleus accumbens neurons via G-protein bg subunits. J Neurosci 23:5079-5087.

Horvitz JC (2002) Dopamine gating of glutamatergic sensorimotor and incentive motivational input signals to the striatum. Behav Brain Res 137:65-74.
Ishikawa A, Ambroggi F, Nicola SM, Fields HL (2007) Contrasting contributions of the prefrontal cortex and amygdala to cue-evoked reward seeking behavior. Soc Neurosci Abstr 33:310.10.

Ito R, Dalley JW, Howes SR, Robbins TW, Everitt BJ (2000) Dissociation in conditioned dopamine release in the nucleus accumbens core and shell in response to cocaine cues and during cocaine-seeking behavior in rats. J Neurosci 20:7489-7495.

Jodo E, Suzuki Y, Kayama Y (2000) Selective responsiveness of medial prefrontal cortex neurons to the meaningful stimulus with a low probability of occurrence in rats. Brain Res 856:68-74.

Johnson LR, Aylward RL, Hussain Z, Totterdell S (1994) Input from the amygdala to the rat nucleus accumbens: its relationship with tyrosine hydroxylase immunoreactivity and identified neurons. Neuroscience 61:851-865.

Kiyatkin EA, Rebec GV (1996) Dopaminergic modulation of glutamateinduced excitation of neurons in the neostriatum and nucleus accumbens of awake, unrestrained rats. J Neurophysiol 75:142-153.

Ljungberg T, Apicella P, Schultz W (1992) Responses of monkey dopamine neurons during learning of behavioral reactions. J Neurophysiol 67:145-163.

McFarland K, Kalivas PW (2001) The circuitry mediating cocaine-induced reinstatement of drug-seeking behavior. J Neurosci 21:8655-8663.

McGeorge AJ, Faull RL (1989) The organization of the projection from the cerebral cortex to the striatum in the rat. Neuroscience 29:503-537.

Mogenson GJ, Jones DL, Yim CY (1980) From motivation to action: functional interface between the limbic system and the motor system. Prog Neurobiol 14:69-97.

Mulder AB, Hodenpijl MG, Lopes da Silva FH (1998) Electrophysiology of the hippocampal and amygdaloid projections to the nucleus accumbens of the rat: convergence, segregation, and interaction of inputs. J Neurosci 18:5095-5102.

Muramoto K, Ono T, Nishijo H, Fukuda M (1993) Rat amygdaloid neuron responses during auditory discrimination. Neuroscience 52:621-636.

Nicola SM (2007) The nucleus accumbens as part of a basal ganglia action selection circuit. Psychopharmacology 191:521-550.

Nicola SM, Surmeier J, Malenka RC (2000) Dopaminergic modulation of neuronal excitability in the striatum and nucleus accumbens. Annu Rev Neurosci 23:185-215.

Nicola SM, Hopf FW, Hjelmstad GO (2004a) Contrast enhancement: a physiological effect of striatal dopamine? Cell Tissue Res 318:93-106.

Nicola SM, Yun IA, Wakabayashi KT, Fields HL (2004b) Cue-evoked firing of nucleus accumbens neurons encodes motivational significance during a discriminative stimulus task. J Neurophysiol 91:1840-1865.

Nicola SM, Yun IA, Wakabayashi KT, Fields HL (2004c) Firing of nucleus accumbens neurons during the consummatory phase of a discriminative stimulus task depends on previous reward predictive cues. J Neurophysiol 91:1866-1882.

Nicola SM, Taha SA, Kim SW, Fields HL (2005) Nucleus accumbens dopamine release is necessary and sufficient to promote the behavioral response to reward-predictive cues. Neuroscience 135:1025-1033.

O’Donnell P, Grace AA (1995) Synaptic interactions among excitatory afferents to nucleus accumbens neurons: hippocampal gating of prefrontal cortical input. J Neurosci 15:3622-3639.

Pan WX, Schmidt R, Wickens JR, Hyland BI (2005) Dopamine cells respond to predicted events during classical conditioning: evidence for eligibility traces in the reward-learning network. J Neurosci 25:6235-6242.

Passetti F, Chudasama Y, Robbins TW (2002) The frontal cortex of the rat and visual attentional performance: dissociable functions of distinct medial prefrontal subregions. Cereb Cortex 12:1254-1268.

Paxinos G, Watson C (1998) The rat brain in stereotaxic coordinates. San Diego: Academic.

Pennartz CM, Groenewegen HJ, Lopes da Silva FH (1994) The nucleus accumbens as a complex of functionally distinct neuronal ensembles: an integration of behavioural, electrophysiological and anatomical data. Prog Neurobiol 42:719-761.

Peters J, Vallone J, Laurendi K, Kalivas PW (2008) Opposing roles for the ventral prefrontal cortex and the basolateral amygdala on the spontaneous recovery of cocaine-seeking in rats. Psychopharmacology (Berl) 197:319-326.

Quirk GJ, Russo GK, Barron JL, Lebron K (2000) The role of ventromedial prefrontal cortex in the recovery of extinguished fear. J Neurosci 20:6225-6231. 
Roitman MF, Stuber GD, Phillips PE, Wightman RM, Carelli RM (2004) Dopamine operates as a subsecond modulator of food seeking. J Neurosci 24:1265-1271.

Saddoris MP, Gallagher M, Schoenbaum G (2005) Rapid associative encoding in basolateral amygdala depends on connections with orbitofrontal cortex. Neuron 46:321-331.

Schoenbaum G, Chiba AA, Gallagher M (1998) Orbitofrontal cortex and basolateral amygdala encode expected outcomes during learning. Nat Neurosci 1:155-159.

Schoenbaum G, Chiba AA, Gallagher M (1999) Neural encoding in orbitofrontal cortex and basolateral amygdala during olfactory discrimination learning. J Neurosci 19:1876-1884.

Schoenbaum G, Setlow B, Saddoris MP, Gallagher M (2003) Encoding predicted outcome and acquired value in orbitofrontal cortex during cue sampling depends upon input from basolateral amygdala. Neuron 39:855-867.

Schultz W (1998) Predictive reward signal of dopamine neurons. J Neurophysiol 80:1-27.

Schultz W, Apicella P, Ljungberg T (1993) Responses of monkey dopamine neurons to reward and conditioned stimuli during successive steps of learning a delayed response task. J Neurosci 13:900-913.

Sesack SR, Pickel VM (1992) Prefrontal cortical efferents in the rat synapse on unlabeled neuronal targets of catecholamine terminals in the nucleus accumbens septi and on dopamine neurons in the ventral tegmental area. J Comp Neurol 320:145-160.

Sesack SR, Deutch AY, Roth RH, Bunney BS (1989) Topographical organization of the efferent projections of the medial prefrontal cortex in the rat: an anterograde tract-tracing study with Phaseolus vulgaris leucoagglutinin. J Comp Neurol 290:213-242.
Swanson LW (1982) The projections of the ventral tegmental area and adjacent regions: a combined fluorescent retrograde tracer and immunofluorescence study in the rat. Brain Res Bull 9:321-353.

Takenouchi K, Nishijo H, Uwano T, Tamura R, Takigawa M, Ono T (1999) Emotional and behavioral correlates of the anterior cingulate cortex during associative learning in rats. Neuroscience 93:1271-1287.

Wan X, Peoples LL (2006) Firing patterns of accumbal neurons during a pavlovian-conditioned approach task. J Neurophysiol 96:652660 .

Weiss F, Maldonado-Vlaar CS, Parsons LH, Kerr TM, Smith DL, Ben-Shahar O (2000) Control of cocaine-seeking behavior by drug-associated stimuli in rats: effects on recovery of extinguished operant-responding and extracellular dopamine levels in amygdala and nucleus accumbens. Proc Natl Acad Sci USA 97:4321-4326.

Xi ZX, Stein EA (1998) Nucleus accumbens dopamine release modulation by mesolimbic GABAA receptors: an in vivo electrochemical study. Brain Res 798:156-165.

Yun IA, Nicola SM, Fields HL (2004a) Contrasting effects of dopamine and glutamate receptor antagonist injection in the nucleus accumbens suggest a neural mechanism underlying cue-evoked goal-directed behavior. Eur J Neurosci 20:249-263.

Yun IA, Wakabayashi KT, Fields HL, Nicola SM (2004b) The ventral tegmental area is required for the behavioral and nucleus accumbens neuronal firing responses to incentive cues. J Neurosci 24:2923-2933.

Zahm DS (2000) An integrative neuroanatomical perspective on some subcortical substrates of adaptive responding with emphasis on the nucleus accumbens. Neurosci Biobehav Rev 24:85-105. 